\title{
In Vitro Activity of Methylene Blue on Mycobacterium Tuberculosis Complex Isolates
}

Deniz GAZEL ( $\sim$ denizgazel@yahoo.com )

\section{Research}

Keywords: Mycobacterium tuberculosis complex, methylene blue, antimicrobial, susceptibility, tuberculosis

Posted Date: May 28th, 2020

DOI: https://doi.org/10.21203/rs.3.rs-31384/v1

License: (c) (i) This work is licensed under a Creative Commons Attribution 4.0 International License. Read Full License 


\section{Abstract}

Background: Methylene blue (MB) is used for bacterial staining, and as an antidote drug. We aimed to investigate the antimicrobial effects of MB against Mycobacterium tuberculosis complex clinical isolates.

Methods: Seventeen stored Mycobacterium tuberculosis complex isolates were inoculated into Mycobacteria Growth Indicator Tubes (MGIT) and incubated in Automated Mycobacterial Detection System (AMDS). MGIT tubes containing MB blue at concentrations of $0.2,2,20,1000 \mu \mathrm{g} \mathrm{ml}^{-1}$ and control were prepared. Antibiograms were performed using AMDS.

Results: Six isolates were susceptible to MB at all concentrations and five were susceptible to only 1000 $\mu \mathrm{g} \mathrm{ml}^{-1} \mathrm{MB}$. Three isolates were susceptible to 1000 and $20 \mu \mathrm{g} \mathrm{ml}^{-1} \mathrm{MB}$. Susceptibility rate was found $94 \%$ when the critical concentration was accepted $400 \mathrm{GU}$ (1/100 of control).

Conclusions: MB may become an alternative anti-tuberculosis agent especially in the topical form of this drug due to their well-known side effects and dosing regimens.

\section{Background}

Mycobacterium tuberculosis complex species share $99.9 \%$ sequence identity and probably evolved from a single clone ${ }^{[1,2]}$. The species Mycobacterium tuberculosis causes the vast majority of human tuberculosis (TB) worldwide. In addition, the Mycobacterium africanum species causes human TB in West Africa, where it accounts for up to $50 \%$ of cases ${ }^{[1,3]}$. Globally, an estimated 10 million people had TB in 2018. The burden of disease varies enormously among countries, from less than $5 / 100,000$ to more than $500 / 100,000$ population per year. There were an estimated 1.2 million TB deaths among HIVnegative people in the year 2018. The latest treatment outcome data for new cases of TB show a global treatment success rate of $85 \%$ in 2017 , an increase of $81 \%$ since $2016^{[4]}$.

The ongoing global burden of TB and the emergence of multi-drug-resistant (MDR) TB have led to increased use of second-line anti-TB drugs ${ }^{[5]}$. Treatment of patients infected with primary anti-TB drugresistant $M$. tuberculosis complex microorganisms, including MDR isolates (resistant to at least isoniazid and rifampicin), constitutes a real clinical challenge. Moreover, tuberculostatic agents against the MDR M. tuberculosis complex remain very limited ${ }^{[6]}$. The emergence of extensively drug-resistant TB (MDR-TB with additional resistance to any fluoroquinolone and to at least one of the three injectable second-line drugs which are amikacin, kanamycin and capreomycin) is worsening the drug resistance problem $[7,8]$. TB and Human Immunodeficiency Virus co-infections, especially in combination with drug resistance, have caused outbreaks with extremely high mortality rates. Moreover, the emergence of XDR-TB has had a dramatic impact on the changing patterns of global TB ${ }^{[9]}$.

Methylene blue (MB), also known as methylthioninium chloride, is a cationic thiazine dye and a heterocyclic aromatic chemical compound which can be used as a drug for various indications in 
medicine ${ }^{[10-12]}$. It is a medication in clinical science and a microbiological dye in laboratory medicine ${ }^{[11}$, $13,14]$. It is used as an antidote to drug-induced methemoglobinaemia, and in surgical sciences for staining of the surgical field ${ }^{[11,15,16]}$. MB reverses hypotension in septic shock, is useful in vasoplegia following cardiopulmonary bypass, and it is recommended for treatment of protamine reactions. It may be helpful in anaphylactic shock, and it has helped to treat hypotension related to lithium toxicity, ACE inhibition, and haemodialysis ${ }^{[11,12]}$. MB can be given intravenously as $1-2 \mathrm{mg} \mathrm{kg}^{-1}$ for the treatment of methemoglobinaemia and it can be administered by intravenous infusion at varying times during parathyroid surgery at doses ranging from $3 \mathrm{mg} \mathrm{kg}^{-1}$ to $7.5 \mathrm{mg} \mathrm{kg}^{-1}[15,17]$. Regarding infectious diseases, MB has been reported to show activity against Plasmodium falciparum strains and to have the potential to be used as an antimalarial agent in combination with other drugs ${ }^{[18]}$. In the literature, there are promising studies reporting positive effects of MB on several pathogens causing infections such as candidiasis, choromoblastomycosis, onychomycosis, malaria, acne vulgaris, Acinetobacter infections and wound-associated bacterial infections due to Staphylococci and E. coli ${ }^{[19-24]}$. Also, it has been claimed to be effective in a topical form for the treatment of chronic dermatologic diseases including lichen planus and psoriasis ${ }^{[25,26]}$.

In this study we aimed to investigate the inhibitory effect of MB compound against $M$. tuberculosis complex clinical isolates in our university hospital. If the inhibitory effect of MB at a clinically achievable concentration could be proved, an alternative anti-TB drug containing MB could be developed in the future.

\section{Material And Methods \\ 2.1. Isolate Selection}

Seventeen non-repetitive $M$. tuberculosis complex clinical isolates which were isolated from tuberculosis patients in our university hospital were included in the study. During routine laboratory work, specimens were cultured using the BACTEC Mycobacteria Growth Indicator Tube (MGIT) 960 Automated Mycobacterial Detection System (AMDS) (Becton Dickinson, USA). The positive cultures were identified by microscopy (Ziehl-Neelsen stain) and the immune chromatographic method using the MGIT TBC Identification Test (Becton Dickinson, USA). Antibiograms for the first-line drugs were also implemented by AMDS. All strains were isolated from the pulmonology clinic in our university hospital between $1 \mathrm{st}$ January 2018 and 1 st January 2019 and stored at $-20^{\circ} \mathrm{C}$ prior to the study.

\subsection{Study Design}

Before the testing stage, the stored isolates were inoculated into MGIT tubes starting from the last isolated (stored) strain in order to increase the rate of viability. The first 20 isolates which gave a growth signal in the AMDS were planned to be included in the study. However, three isolates were excluded from the study due to a contamination in the MB testing stage. In the testing stage, the MGIT 960 AMDS 
system was modified for MB testing and $0.2,2,20$ and $1000 \mu \mathrm{g} \mathrm{ml}^{-1}$ concentrations of MB were used instead of the critical concentrations of the four first-line anti-tuberculosis drugs (Figure 1.). In the cultivation stage, stored isolates were inoculated into MGIT tubes and incubated until the AMDS gave a positive signal for growth. Then, four MGIT tubes containing MB blue at concentrations of $0.2,2,20$ and $1000 \mu \mathrm{g} \mathrm{ml}^{-1}$ were prepared (Figure 2.). On the next day, four testing tubes were inoculated from the positive MGIT tube according to the manufacturer's recommendations in accordance with the MGIT protocol of susceptibility testing for first-line anti-tuberculosis drugs ${ }^{[27]}$. A control tube (1/100 dilution) was prepared in the same way. When the diluted control tube reached 400 growth units (GU), the AMDS gave a positive signal and the results were interpreted. If the growing rate was $>100 \mathrm{GU}$ in an MB tube, the isolate was determined to be resistant to this concentration of $\mathrm{MB}$; if the growing rate was $<=100 \mathrm{GU}$, it was determined to be susceptible ${ }^{[27]}$. If the growing rate was between 100 and $400 \mathrm{GU}$, the result was determined as borderline.

\section{Results}

A total of $17 \mathrm{M}$. tuberculosis complex clinical isolates showing different antibiogram patterns were included in the study. According to previous AMDS antibiogram results which were obtained during routine laboratory work (before the study), two isolates (12\%) were mono-drug-resistant, five isolates (29\%) were poly-drug-resistant and ten isolates (59\%) were susceptible to all first-line anti-tuberculosis agents. The antibiogram patterns of the isolates for primary (first-line) anti-tuberculosis drugs are shown in Table 1. 
Table 1

Antibiogram profiles of the isolates for the first-line drugs and MB compound via Automated Mycobacterial Detection System

\begin{tabular}{|c|c|c|c|c|c|c|c|c|}
\hline \multicolumn{5}{|c|}{ First Line Drugs } & \multicolumn{4}{|c|}{$\begin{array}{l}\text { Growth Units of Isolates at Critical Concentrations of } \\
\text { Methylene Blue }\end{array}$} \\
\hline No: & STR & INH & RIF & ETA & $\begin{array}{l}1000 \\
\mu \mathrm{g} \mathrm{ml}^{-1}\end{array}$ & $\begin{array}{l}20 \\
\mu \mathrm{g} \mathrm{ml}^{-1}\end{array}$ & $\begin{array}{l}2 \\
\mu \mathrm{g} \mathrm{ml}^{-1}\end{array}$ & $0.2 \mu \mathrm{g} \mathrm{ml}^{-1}$ \\
\hline 1 & S & S & $S$ & S & 0 & 0 & 0 & 0 \\
\hline 2 & S & $S$ & $S$ & S & 6 & 0 & 0 & 0 \\
\hline 3 & $\mathrm{R}$ & $\mathrm{R}$ & $\mathrm{R}$ & $\mathrm{R}$ & 160 & 400 & 400 & 400 \\
\hline 4 & S & $\mathrm{S}$ & $\mathrm{S}$ & S & 0 & 0 & 0 & 0 \\
\hline 5 & S & $\mathrm{R}$ & $\mathrm{R}$ & S & 400 & 400 & 400 & 400 \\
\hline 6 & $\mathrm{R}$ & $S$ & $S$ & S & 0 & 8 & 143 & 357 \\
\hline 7 & S & $\mathrm{R}$ & $S$ & S & 7 & 103 & 400 & 400 \\
\hline 8 & S & $S$ & $\mathrm{R}$ & S & 0 & 0 & 0 & 8 \\
\hline 9 & $\mathrm{R}$ & $S$ & $S$ & S & 0 & 9 & 400 & 400 \\
\hline 10 & S & $S$ & $S$ & S & 7 & 0 & 6 & 0 \\
\hline 11 & S & $\mathrm{R}$ & $S$ & S & 0 & 1 & 0 & 66 \\
\hline 12 & S & $\mathrm{S}$ & $S$ & S & 0 & 400 & 400 & 400 \\
\hline 13 & S & $S$ & $S$ & S & 0 & 400 & 400 & 400 \\
\hline 14 & S & $S$ & $S$ & $S$ & 0 & 103 & 400 & 400 \\
\hline 15 & S & $S$ & $S$ & $S$ & 305 & 400 & 400 & 400 \\
\hline 16 & S & $S$ & $S$ & $S$ & 8 & 102 & 136 & 400 \\
\hline 17 & $S$ & S & $S$ & $S$ & 62 & 85 & 400 & 400 \\
\hline
\end{tabular}

In the testing stage for $\mathrm{MB}$, six isolates (three mono-drug-resistant and three susceptible) were found to be susceptible to MB at all concentrations $\left(0.2\right.$ to $1000 \mathrm{~g} \mathrm{ml}^{-1}$ ). Five isolates (four susceptible and one mono-drug-resistant) were susceptible to only $1000 \mathrm{~g} \mathrm{ml}^{-1}$ of MB concentration. Three isolates (two 
mono-drug-resistant and one susceptible) were susceptible to $1000 \mu \mathrm{g} \mathrm{ml}^{-1}$ and $20 \mathrm{\mu g} \mathrm{ml}^{-1} \mathrm{MB}$ concentrations, and three isolates (two multi-drug-resistant and one susceptible) were resistant to all concentrations of MB if the critical concentration is accepted as $100 \mathrm{GU}$.

In our study, $1000 \mu \mathrm{g} \mathrm{ml}^{-1}$ concentration of MB inhibited $82 \%$ of the Mycobacterium tuberculosis complex isolates. If the two borderline resistant clinical isolates ( $<400 \mathrm{GU}$ and $>100 \mathrm{GU}$ ) are accepted as susceptible, the rate of inhibition rises to $94 \%$ at the $1000 \mu \mathrm{g} \mathrm{ml}^{-1}$ concentration. The results are summarised in Table 1.

\section{Discussion}

A heterocyclic thiazole derivate, benzothiazinone BTZ043 was reported to be one of the most potent inhibitors of $M$. tuberculosis yet described and displayed bactericidal activity both in vitro and in ex vivo models of TB ${ }^{[28-30]}$. Previously, similar heterocyclic phenothiazine derivates such as thioridazine and toluidine blue were investigated and reported to be effective for treatment of pulmonary tuberculosis; however, we could not find any studies investigating the inhibitory effects of MB (another phenothiazine derivate) on $M$. tuberculosis complex clinical isolates ${ }^{[31,32]}$. Another similar phenothiazine compound chlorpromazine was shown to be effective on $M$. tuberculosis complex isolates; however, it was later understood that the inhibitory concentration of chlorpromazine was many times higher than the safely achievable dose in the patient ${ }^{[33,34]}$. Based upon the data collected for thioridazine, after novel investigations, it was reported that there could be at least four mechanisms by which this phenothiazine compound acts on Mycobacterium tuberculosis. The effect may occur by increasing the killing activity of human macrophages, by inhibiting over-expressed efflux pump and oxygen consumption of the pathogen, and by reaching higher concentrations of thioridazine than MIC or MBC of the bacterium ${ }^{[32]}$. Since methylene blue is a similar heterocyclic phenothiazine derivate, several studies investigating the antimicrobial effect of this compound against Mycobacteria other than tuberculosis have been performed by scientists. Shim et al. reported the inhibitory effect of methylene blue-mediated photodynamic therapy on Mycobacterium smegmatis in $2016^{\text {[35] }}$. One year later, Pal et al. conducted research on Candida albicans and Mycobacterium smegmatis and stated that MB alone inhibited the growth of Mycobacterium smegmatis at $15.62 \mathrm{~g} \mathrm{ml}^{-1}$ in a bacteriostatic manner similar to its fungistatic characteristic (Myco-bacteria means fungus-like bacteria in Greek) ${ }^{[36]}$. They also reported that MB was leading to impaired cell surface phenotypes, altered colony morphologies, and DNA damage in Mycobacteria. They suggested performing further investigations on Mycobacterium tuberculosis, since this pathogen contains unique cell envelope components with complex lipids providing pathogenicity [36]. However, in the literature, there are no reports investigating the effects of MB on $M$. tuberculosis complex clinical isolates. Our study might be the first in vitro non-photodynamic research investigating the antimicrobial effect of MB compound on Mycobacterium tuberculosis complex clinical isolates and showing the potential of MB alone for treatment of tuberculosis infection. 
In our study, we investigated four different critical concentrations of MB because MB can be used as a drug in different forms for different indications (topical, oral or intravenous) and varied concentrations of MB can be found in several drug types. In a previous study, Walter-Sac et al. reported that MB plasma

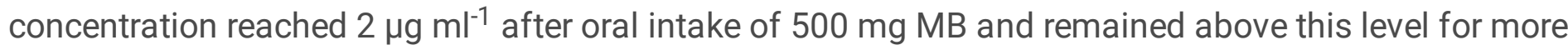
than five hours in healthy individuals. They also showed that MB plasma concentration reached $0.2 \mu \mathrm{g}$ $\mathrm{ml}^{-1}$ after intravenous injection of $50 \mathrm{mg} \mathrm{MB}$ and remained above this level for more than seven hours [37]. In two other studies investigating the bioavailability of MB tablets, the areas under curve 0-t [AUC (0t)] were found to be about 25 and $33 \mathrm{\mu g} \mathrm{ml}^{-1} \times$ hour after intake of $200 \mathrm{mg} \mathrm{MB}^{[38,39]}$. In another study investigating the pharmacokinetics and organ distributions of intravenous and oral methylene blue, it was shown that much higher concentrations of MB were reached in some organs than in blood. In the animal models, twenty-fold higher concentrations than in blood were found in the brain following administration of intravenous $\mathrm{MB}{ }^{[40]}$.

When we compare these studies with the findings of our research, the critical concentration of MB at 2 $\mu \mathrm{g} \mathrm{ml}^{-1}$ which inhibited $35 \%$ of our study isolates could have potential as an alternative anti-tuberculosis drug. When we accept $20 \mu \mathrm{g} \mathrm{ml}^{-1}$ as a target critical MB concentration, $53 \%$ of the isolates could be inhibited by administration of MB. If we take three isolates (isolate no: 7,14 , and 16) with borderline inhibition $(103,103$, and $102 \mathrm{GU})$ into consideration, the rate of susceptibility rises to $70 \%$ at the $20 \mu \mathrm{g} \mathrm{ml}^{-}$ ${ }^{1}$ critical concentration. Since the proportion method accepts the resistance breakpoint as $1 \%$ (equal to $400 \mathrm{GU})$ of the control population, these borderline values may also be accepted as susceptible ${ }^{[41,42]}$. Secondly, the ability of MB to cross the blood-brain barrier and diffuse inside the brain at higher concentrations than blood could make MB attractive as a potential therapeutic agent for central nervous system infection such as TB meningitis and TB encephalitis ${ }^{[40]}$.

In the literature, there are some clinical studies investigating the effects of the topical form of MB against dermatological diseases such as fungal infections, acne vulgaris, psoriasis, and lichen planus $[20,21,25$, 26]. In these studies, the cream, hydro-gel and solution forms of MB were prepared at the concentrations of 500,1000 and $200,000 \mathrm{~g} \mathrm{ml}^{-1}$ for photodynamic therapy (not for tuberculosis) and they were found to be effective for treating patients, without any significant side effects. Comparing the MB doses of these topical preparations with our results, $1000 \mathrm{~m} \mathrm{ml}^{-1}$ concentration of $\mathrm{MB}$ inhibited $82 \%$ of the Mycobacterium tuberculosis complex isolates in our study. If the two borderline resistant clinical isolates ( $<400 \mathrm{GU}$ and $>100 \mathrm{GU}$ ) are accepted as susceptible, the rate of inhibition rises to $94 \%$ at $1000 \mathrm{~g} \mathrm{ml}^{-1}$ concentration. We know that Mycobacterium tuberculosis complex may also cause mucosal and cutaneous infections. So, topical drugs containing much higher MB concentrations (e.g. at $1000 \mu \mathrm{g} \mathrm{ml}^{-1}$ ) may be used to treat local cutaneous infections due to Mycobacterium tuberculosis complex ${ }^{[43]}$. In our study only one (4\%) MDR isolate (No.:5) was found resistant to MB at all concentrations and second MDR isolate (No.:3) was resistant to MB at $0.2,2$, and $20 \mu \mathrm{g} \mathrm{ml}^{-1}$ critical concentrations. 
The agar proportion method is the accepted "gold" standard for first-line antimicrobial susceptibility testing of Mycobacterium tuberculosis complex isolates. But this method is labour intensive and requires a calculation by counting colonies. In this method, if there is $\geq 1 \%$ growth on the drug-containing medium as compared to the drug-free medium, the organism is considered resistant ${ }^{[41,42]}$. The MGIT 960 AMDS uses a similar broth proportion method and the system is currently recommended by the WHO as the gold standard for second-line drug susceptibility testing ${ }^{[44]}$. Since the aim of this study is to investigate MB as a novel and alternative (second-line) anti-tuberculosis drug, MGIT 960 AMDS was included in the study. In a multicentre study, levofloxacin, amikacin, capreomycin, and ethionamide drugs were investigated and the overall agreement between the agar proportion method and the MGIT 960 AMDS was found to be $96.4 \%{ }^{[45]}$. Thus, the AMDS system is not only practical but also has a good agreement with the proportion method.

\section{Conclusions}

Since resistance development has emerged as a significant problem in the treatment of tuberculosis, the discovery of new anti-tuberculosis drugs has gained importance. In this study, we showed that $35 \%$ of isolates were inhibited by MB even at the lowest dose $\left(0.2 \mu \mathrm{g} \mathrm{ml}^{-1}\right)$ and $82 \%$ of the isolates were susceptible to the highest concentration $\left(1000 \mu \mathrm{g} \mathrm{ml}^{-1}\right)$ of MB. When the critical concentration was accepted as $400 \mathrm{GU}(1 / 100$ of the control), MB was effective on $94 \%$ of the isolates at the MB concentration of a topical drug form. We believe that MB may become an alternative anti-tuberculosis agent especially in the topical form of this drug. As an advantage, various topical and parenteral forms of FDA-approved MB preparations are available on the market. Thus, it could be easier to treat different types of tuberculosis disease using these drug forms because of their well-known side effects and dosing regimens ${ }^{[48]}$. As a second advantage, $\mathrm{MB}$ is a cheap and naive drug which is not in routine use for any infection. If we can confirm our results with more in vivo and in vitro experiments, MB could become an alternative anti-tuberculosis drug in the future.

\section{Abbreviations}

Methylene blue, MB; Mycobacteria Growth Indicator Tubes, MGIT; Automated Mycobacterial Detection System, AMDS; Tuberculosis, TB; Growth Unit, GU; Multi-Drug Resistant, MDR; Extensively drug-resistant, XDR;

\section{Declaration}

\section{Appendices}

Competing interests: The author declares there are no competing interests.

Ethical approval. EA was obtained from the Clinical Research Ethics Committee of XXXX University with date and number: $18.12 .2018 ; 2018 / 381$. 
Funding: No public or private funding/grant was received for this study.

Assistance: I would like to thank my laboratory technicians, XXX XXX and XXX XXX for their technical assistance during the study.

Proofreading. Proofreading was performed by Anchor English Editing Service

\section{References}

1. Fitzgerald DW, Sterling TR, Haas DW. Mycobacterium tuberculosis. In: Bennett JE, Dolin R, Blaser MJ (editors). Mandell, Douglas and Bennettes's principles and practise of infectious diseases, 8 th ed. Philadelphia: Elsevier Inc; 2015. pp. 2787-2818.

2. Ernst JD, Trevejo-Nuñez G, Banaiee N. Genomics and the evolution, pathogenesis, and diagnosis of tuberculosis. J Clin Invest 2007;117(7):1738-1745 DOI: 10.1172/JCI31810

3. de Jong BC, Antonio M, Gagneux S. Mycobacterium africanum-review of an important cause of human tuberculosis in West Africa. PLoS Negl Trop Dis 2010;4(9):e744 DOI:

10.1371/journal.pntd.0000744

4. Global Tuberculosis Report Executive Summary 2019. World Health Organization; 2019. 8p. Report No.: WHO/CDS/TB/2019.23. Available from: https://www.who.int/tb/publications/global_report/tb19_Exec_Sum_12Nov2019.pdf?ua=1

5. Richter E, Rusch-Gerdes S, Hillemann D. First linezolid-resistant clinical isolates of Mycobacterium tuberculosis. Antimicrob Agents Chemother. 2007;51(4):1534-1536 DOI: 10.1128/AAC.01113-06

6. Tato M, de la Pedrosa EG, Canton R, Gomez-Garcia I, Fortun J, Martin-Davila P, et al. In vitro activity of linezolid against Mycobacterium tuberculosis complex, including multidrug-resistant Mycobacterium bovis Int J Antimicrob Agents. 2006;28(1):75-78 DOI: 10.1016/j.jjantimicag.2006.02.011

7. World Health Organization: Multidrug and extensively drug-resistant TB (M/XDR-TB) 2010 Global report on surveillance and response. France: World Health Organization; 2010. 71p. Report No.: WHO/HTM/TB/2010.3.

8. Centers for Disease Control and Prevention: Notice to readers: Revised definition of extensively drugresistant tuberculosis. Report No.: MMWR 2006/55(43):1176. Available from:

https://www.cdc.gov/mmwr/preview/mmwrhtml/mm5543a4.htm

9. Gandhi NR, Shah NS, Andrews JR, Vella V, Moll AP, Scott M, et al. HIV coinfection in multidrug- and extensively drug-resistant tuberculosis results in high early mortality. Am J Respir Crit Care Med. 2010;181(1):80-86 DOI: 10.1164/rccm.200907-09890C

10. PubChem Database [Internet]. U.S. National Library of Medicine, National Center for Biotechnology Information; 2020. Methylene blue; [about 77 pages]. Available from: https://pubchem.ncbi.nlm.nih.gov/compound/Methylene-blue

11. Misclescu A, Wiklund L. Methylene blue, an old drug with new indications? Rom J Anaesth Intensive Care. 2010;17(1):35-41. 
12. Barrett NM, Alston TA. Literature reviews: Methylene blue added to a hypertonic-hyperoncotic solution increases shorttime survival in experimental cardiac arrest. ASA Newsletter. 2006;5:7-8 DOI: 10.1097/01.CCM.0000242517.23324.27

13. Levin M. Differentiation of coli and $A$. aerogenes on a simplified eosin-methylene blue agar. $J$ Infect Dis. 1918;23:43-47.

14. Wainwright M, Crossley KB. Methylene blue-a therapeutic dye for all seasons? J. Chemother. 2002;14(5):431-443 DOI: 10.1179/joc.2002.14.5.431

15. Barclay JA, Ziemba SE, Ibrahim RB. Dapsone-induced methemoglobinemia: a primer for clinicians. Ann Pharmacother. 2011;45(9):1103-1115 DOI: 10.1345/aph.1Q139

16. Mathelin C, Croce S, Brasse D, Gairard B, Gharbi M, Andriamisandratsoa N, et al. Methylene blue dye, an accurate dye for sentinel lymph node identification in early breast cancer. Anticancer Res. 2009; 29(10):4119-4125

17. Pollack G, Pollack A, Delfiner J, Fernandez J. Parathyroid surgery and methylene blue: a review with guidelines for safe intraoperative use. Laryngoscope. 2009;119(10):1941-1946 DOI:

10.1002/lary.20581

18. Pascual A, Henry M, Briolant S, Charras S, Baret E, Amalvict R, et al. In vitro activity of Proveblue (methylene blue) on Plasmodium falciparum strains resistant to standard antimalarial drugs. Antimicrob Agents Chemother. 2011;55(5):2472-2474 DOI: 10.1128/AAC.01466-10

19. Gazel D, Tatman Otkun M, Akçalı A. In vitro activity of methylene blue and eosin methylene blue agar on colistin-resistant baumannir: an experimental study. J Med Microbiol. 2019;68(11):1607-1613. Available from: https://www.microbiologyresearch.org/content/journal/jmm/10.1099/jmm.0.001078 DOI: 10.1099/jmm.0.001078

20. Lyon JP, Pedroso e Silva Azevedo Cde M, Moreira LM, de Lima CJ, de Resende MA. Photodynamic antifungal therapy against chromoblastomycosis. Mycopathologia. 2011;172(4):293-297 DOI: 10.1007/s11046-011-9434-6

21. Fadel M, Salah M, Samy N, Mona S. Liposomal methylene blue hydrogel for selective photodynamic therapy of acne vulgaris. J Drugs Dermatol. 2009;8(11):983-990.

22. Tardivo JP, Del Giglio A, de Oliveira CS, Gabrielli DS, Junqueira HC, Tada DB, et al. Methylene blue in photodynamic therapy: From basic mechanisms to clinical applications. Photodiagnosis and Photodynamic Therapy. 2005;2(3):175-191 DOI: 10.1016/S1572-1000(05)00097-9

23. Kashef N, Esmaeeli Djavid G, Siroosy M, Taghi Khani A, Hesami Zokai F, Fateh M. Photodynamic inactivation of drug-resistant bacteria isolated from diabetic foot ulcers. Iran J Microbiol. 2011;3(1):36-41.

24. Lu G, Nagbanshi M, Goldau N, Mendes Jorge M, Meissner P, Jahn A, et al. Efficacy and safety of methylene blue in the treatment of malaria: A systematic review. BMC Med [Internet]. 2018;25(16):59. Available from: https://bmcmedicine.biomedcentral.com/articles/10.1186/s12916-018-1045-3 DOI: 10.1186/s12916-018-1045-3 
25. Aghahosseini F, Arbabi-Kalati F, Fashtami LA, Fateh M, Djavid GE. Treatment of oral lichen planus with photodynamic therapy mediated methylene blue: a case report. Med Oral Patol Oral Cir Bucal. 2006 Mar 1;11(2):126-129.

26. Salah M, Samy N, Fadel M. Methylene blue mediated photodynamic therapy for resistant plaque psoriasis. J Drug Dermatol. 2009;8(1):42-49.

27. Siddiqi SH, Rüsch-Gerdes S. MGIT Procedure Manual. Foundation for Innovative Diagnostics; 2006. 89 pages. Available from: https://www.finddx.org/wpcontent/uploads/2016/02/mgit_manual_nov2006.pdf

28. Makarov V, Lechartier B, Zhang M, Neres J, van der Sar AM, Raadsen SA, et al. Towards a new combination therapy for tuberculosis with next generation benzothiazinones. EMBO Mol Med. 2014;6(3):372-383 DOI: 10.1002/emmm.201303575

29. Makarov V, Manina G, Mikusova K, Mollmann U, Ryabova O, Saint-Joanis B, et al. Benzothiazinones kill Mycobacterium tuberculosis by blocking arabinan synthesis. Science. 2009;324(5928):801-804 DOI: 10.1126/science.1171583

30. Neres J, Pojer F, Molteni E, Chiarelli LR, Dhar N, Boy-Röttger S, et al. Structural basis for benzothiazinone-mediated killing of Mycobacterium tuberculosis. Sci Transl Med. 2012;4(150):150ra121 DOI: 10.1126/scitranslmed.3004395

31. Grosse-Schönepauck D. Toluidine blue-a tuberculostatic substance? Dtsch Med Wochenschr 1970;95:786-787.

32. Amaral L, Martins A, Spengler G, Hunyadi A, Molnar J. The mechanism by which the phenothiazine thioridazine contributes to cure problematic drug-resistant forms of pulmonary tuberculosis: recent patents for "new use". Recent Pat Antiinfect Drug Discov. 2013;8(3):206-212 DOI: 10.2174/1574891x08666131210141521

33. Molnár J, Béládi I, Földes I. Studies on antituberculotic action of some phenothiazine derivatives in vitro. Zentralbl Bakteriol Orig A. 1977;239:521-526.

34. Kristiansen JE, Vergmann B. The antibacterial effect of selected phenothiazines and thioxanthenes on slow-growing mycobacteria. Acta Pathol Microbiol Immunol Scand B. 1986;94(6):393-398 DOI: 10.1111/j.1699-0463.1986.tb03073.x

35. Shim I, Choi M, Min Y, Seok KH, Kim JK, Jeong JY, et al. Effect of methylene blue-mediated photodynamic therapy on wild-type and ciprofloxacin-resistant Mycobacterium smegmatis. J Bacteriol Virol. 2016;46(1):27-35. DOI:10.4167/jbv.2016.46.1.27

36. Pal R, Ansari MA, Saibabu V, Das S, Fatima Z, Hameed S. Nonphotodynamic roles of methylene blue: display of distinct antimycobacterial and anticandidal mode of actions. J Pathog. 2018;3759704. Available from: https://www.hindawi.com/journals/jpath/2018/3759704/ DOI: https://doi.org/10.1155/2018/3759704

37. Walter-Sack I, Rengelshausen J, Oberwittler H, Burhenne J, Mueller O, Meissner P, et al. High absolute bioavailability of methylene blue given as an aqueous oral formulation. Eur $\mathrm{J}$ Clin Pharmacol. 2009;65(2):179-189 DOI: 10.1007/s00228-008-0563-x

Page $11 / 14$ 
38. Di Stefano AF, Radicioni MM, Vaccani A, Fransioli A, Longo L, Moro L, et al. Methylene blue MMX tablets for chromoendoscopy. Bioavailability, colon staining and safety in healthy volunteers undergoing a full colonoscopy. Contemp Clin Trials. 2018;71:96-102 DOI: 10.1016/j.cct.2018.06.001

39. Repici A, Di Stefano AF, Radicioni MM, Jas V, Moro L, Danese S. Methylene blue MMX tablets for chromoendoscopy. Safety tolerability and bioavailability in healthy volunteers. Contemp Clin Trials. 2012;33(2):260-267.

40. Peter C, Hongwan D, Küpfer A, Lauterburg BH. Pharmacokinetics and organ distribution of intravenous and oral methylene blue. Eur J Clin Pharmacol. 2000;56(3):247-250 DOI: https://doi.org/10.1007/s002280000124

41. Canetti G, Froman S, Grosset J, Hauduroy P, Langerova M, Mahler HT, et al. Mycobacteria: Laboratory methods for testing drug sensitivity and resistance. Bull World Health Organ. 1963;29:565-78.

42. Barth Reller L, Weinstein MP, Woods GL. Susceptibility Testing for Mycobacteria. Clin Infect Dis. 2000;31(5):1209-1215. DOI: 1086/317441

43. Bravo FG, Gotuzzo E. Cutaneous tuberculosis. Clin Dermatol. 2007;25(2):173-180 DOI: 10.1016/j.clindermatol.2006.05.005

44. Framework for implementing new tuberculosis diagnostics. Geneva, Switzerland: World Health Organization; 2010. 24 p. Available from: https://www.who.int/tb/laboratory/whopolicyframework_july10_revnov10.pdf

45. Lin SY, Desmond E, Bonato D, Gross W, Siddiqi S. Multicenter evaluation of Bactec MGIT 960 system for second-line drug susceptibility testing of Mycobacterium tuberculosis $\mathrm{J}$ Clin Microbiol. 2009;47(11):3630-3634. DOI: 10.1128/JCM.00803-09.

Committee for Medicinal Products for Human Use. Assessment report, Methylthioninium chloride Proveblue. London, UK. European Medicines Agency; 2011. 47 p. Report No.: EMEA/H/C/002108. Available from: https://www.ema.europa.eu/en/documents/assessment-report/methylthioniniumchloride-proveblue-epar-public-assessment-report_en.pdf

\section{Figures}




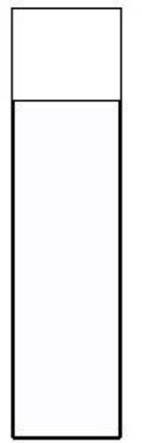

MGIT tube for growth control (no MB)

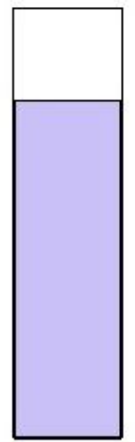

MGIT tube including $0.2 \mu \mathrm{g} \mathrm{ml}^{-1} \mathrm{MB}$

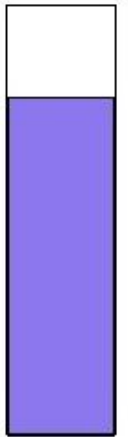

MGIT tube including

$2 \mu \mathrm{g} \mathrm{ml}^{-1} \mathrm{MB}$

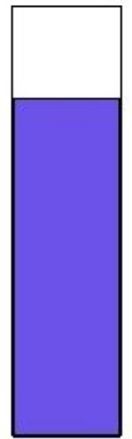

MGIT tube including $20 \mu \mathrm{g} \mathrm{ml}^{-1} \mathrm{MB}$

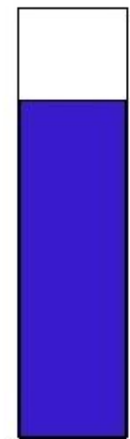

MGIT tube including $1000 \mu \mathrm{g} \mathrm{ml}^{-1} \mathrm{MB}$
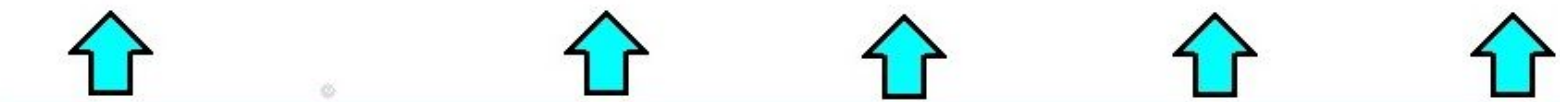

Fluorescence Reader

\section{Figure 1}

Antimicrobial susceptibility testing principle for methylene blue *MGIT 960 tubes containing bacteria and $0.2,2,20$, and $1000 \mu \mathrm{g} \mathrm{ml}-1$ methylene blue were prepared. $* \star$ The florescence levels indicating the bacterial growth were online monitored using Automated Mycobacterial Detection System. ${ }^{\star \star \star} \mathrm{MB}$ :

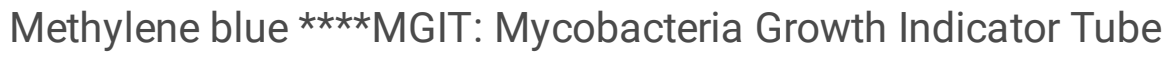




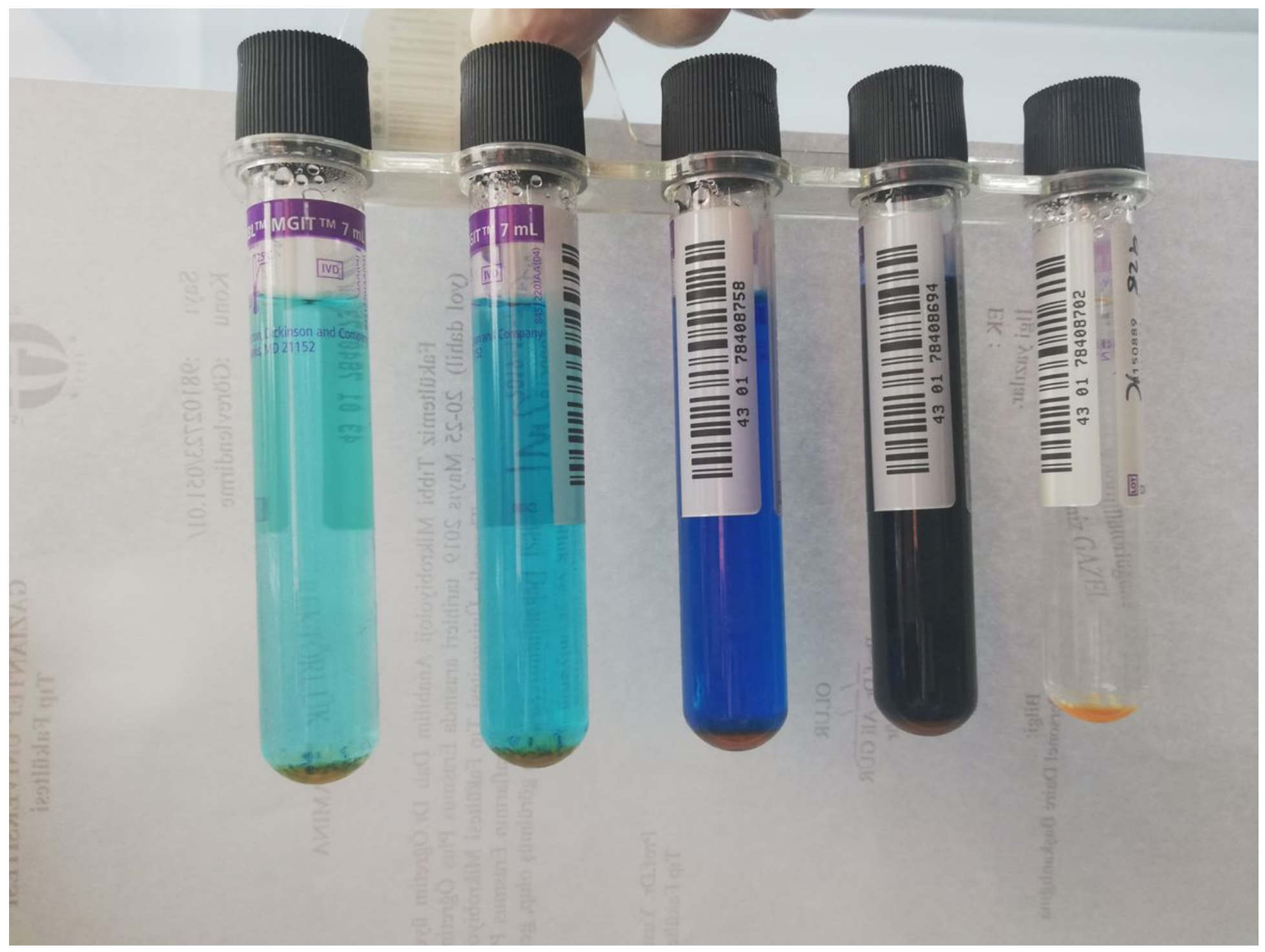

Figure 2

MGIT 960 antibiogram tubes containing increasing concentrations of methylene blue *MGIT 960 tubes containing $0.2,2,20$, and $1000 \mu \mathrm{g} \mathrm{ml}-1$ methylene blue and growth control (left to right).

\section{Supplementary Files}

This is a list of supplementary files associated with this preprint. Click to download.

- ethicalcommiteeapprovalMMTBC.pdf 